ISSN 0103-5150

Fisioter. Mov., Curitiba, v. 24, n. 2, p. 275-283, abr./jun. 2011

Licenciado sob uma Licença Creative Commons

\title{
Intervening factors in the walking of children presenting myelomeningocele
}

\author{
Fatores intervenientes na marcha de crianças com mielomeningocele
}

\section{Dirce Shizuko Fujisawa ${ }^{[a]}$, Marcia Larissa Cavallari da Costa Gois ${ }^{[\mathrm{b}]}$, Josilainne Marcelino Dias ${ }^{[\mathrm{c}}$, Egle de Oliveira Netto Moreira Alves ${ }^{[\mathrm{d}]}$, Marcelo de Souza Tavares ${ }^{[\mathrm{e}]}$, Jefferson Rosa Cardoso ${ }^{[\mathrm{f}]}$}

[a] PT, PhD, professora do Programa de Mestrado em Ciências da Reabilitação (UEL - UNOPAR) e do Departamento de Fisioterapia da Universidade Estadual de Londrina (UEL), Londrina, PR - Brasil, e-mail: dirce_fujisawa@uel.br

[b] PT, Residente em Pediatria Fisioterapia, Universidade Estadual de Londrina (UEL), Londrina, PR - Brasil, e-mail: lariscavallari@hotmail.com

[c] PT, Mestranda em Ciências da Reabilitação (UEL - UNOPAR), Universidade Estadual de Londrina (UEL), Londrina, PR Brasil, e-mail: lainne@hotmail.com

[d] PT, MSc, professor do Departamento de Fisioterapia da Universidade Estadual de Londrina (UEL), Londrina, PR - Brasil, e-mail: eglenetto@hotmail.com

[e] MD, PhD, professor do Departamento de Pediatria da Universidade Federal de Minas Gerais, Minas Gerais, MG - Brasil, e-mail: tavares.marc@gmail.com

[f] PT, PhD, professor do Programa de Mestrado em Ciências da Reabilitação (UEL - UNOPAR) e do Departamento de Fisioterapia da Universidade Estadual de Londrina (UEL), Londrina, PR - Brasil, e-mail: jeffcar@uel.br

\section{Abstract}

Introduction: All children presenting myelomeningocele are capable of walking. Certain interventions can influence the walking prognosis of these children: physical therapy, medication, and nutritional orientation. Objectives: The aim of this study was to verify the association between ability to walk in children with myelomeningocele and clinical, socioeconomic and therapeutic factors. Method: This cross-sectional study was conducted at the University Hospital. The participants were children aged two years-old or more, diagnosed with myelomeningocele. Data collection was conducted by physical therapy assessment and medical records. The dependent variable was walking and the independent variables were clinical, socioeconomic and therapeutic factors. Results: Forty-one children were evaluated, with a median age of 5 years-old (2-9). The clinical factors that revealed an association with walking were neurological area $(\mathrm{p}<$ 
$0,0001)$ and fractures $(p=0,022)$. Socioeconomic factors showed not to be significant in relation to ability to walk. Surgery $(p=0,017)$ and the use of assistive devices $(p=0,023)$ were also associated with the ability to walk. Conclusion: The determinant clinical factor for walking prognosis was the neurological area. The use of assistive devices and surgical intervention were shown to be necessary for promoting walking activity.

Keywords: Gait. Children. Myelomeningocele.

\section{Resumo}

Introdução: Todas as crianças com mielomeningocele são capazes de andar. Certas intervenções podem influenciar no prognóstico de marcha destas crianças: fisioterapia, medicação e orientação nutricional. objetivo: Foi verificar a associação entre a capacidade de andar em crianças com mielomeningocele e fatores clínicos, socioeconômicos e terapêuticos. Método: Estudo transversal realizado no Hospital Universitário. Os participantes foram crianças de dois ou mais anos de idade com diagnóstico de mielomeningocele. A coleta de dados foi realizada por avaliação de um fisioterapeuta e em prontuários médicos. A variável dependente foi o prognóstico de marcha e as variáveis independentes foram os fatores clínicos, socioeconômicos e terapêuticos. Resultados: Foram avaliadas 41 crianças com idade média de cinco anos (2-9). Os fatores clínicos que apresentaram associação com a marcha foram o segmento neurológico $(p<0,0001)$ e as fraturas $(p=$ $0,022)$. Fatores socioeconômicos não se mostraram estatisticamente significantes em relação à capacidade de andar. Cirurgia $(p=0,017)$ e o uso de dispositivos de apoio $(p=0,023)$ também revelaram associação com a marcha. Conclusão: $O$ fator clínico determinante para a capacidade de desenvolver marcha foi o segmento neurológico. A intervenção cirúrgica e o uso de dispositivos auxiliares demonstraram ser necessários na promoção da marcha.

Palavras-chave: Marcha. Crianças. Mielomeningocele.

\section{Introduction}

Myelomeningocele is one of the most serious and frequent congenital anomalies. Studies demonstrate that the occurrence of myelomeningocele involves genetic, environmental and dietary factors (1-2). The incidence is variable, ranging from 1 to 10 per 1.000 births, according to geography and the ethnic origin of the parents (3). Clinical manifestations are flaccid paralysis; diminished muscular force; muscular atrophy; diminished or loss of sensitivity and tendon reflexes; and alterations in vesicle, intestinal function and hydrocephalus (4).

The main concern for the health care team and parents after myelomeningocele diagnosis is the survival of the children, since this requires fetal correction or surgical intervention in the first 24 to 48 hours of life and antibiotic therapy. Later, the therapeutic focus shifts to the child's functional independence, especially, in relation to the possibility of walking.

The ability to walk is directly related to the neurological segments (2). All children presenting myelomeningocele are capable of walking, given that they present normal functioning of the upper limbs, adequate spinal stability, capacity to raise the pelvis, and present hip and trunk mobility (5). Walking and the requirement for orthotics and assistive devices for locomotion are not the same in children presenting the same neurological dysfunction (6).

The clinical manifestations and complications could demand clinical intervention and multiprofessional follow-up (7). Certain interventions can influence the walking ability of children with myelomeningocele: physical therapy, which can promote motor development and gait training; medication, required to treat urinary infection; and nutritional orientation as related to alimentary control in order to avoid obesity. Moreover, orthopedic corrections are fundamental to promote the alignment of the lower limbs and should be conducted prior to the onset of walking. Thus, the aim of this study was to verify the association between the ability to walk in children with myelomeningocele with clinical, socioeconomic and therapeutic factors. 


\section{Method}

This cross-sectional study was conducted at the University Hospital. Only participants with a diagnosis of myelomeningocele, aged two years or older, were selected, since this period is usually sufficient to define the mode of locomotion, and the sample size was considered by convenience. The subjects (parents) provided a voluntary written informed consent, which received the approval of the Ethics Committee on Human Experimentation of the Institution involved (037/04).

Data were collected by physical therapy assessment and additional data was determined by consultation of the patient's medical records. The protocol consisted of four parts: identification data, socioeconomic conditions, therapeutic aspects (clinical and surgical interventions) and physical therapy evaluation. The identification data required information regarding age, gender, area of origin (urban or rural) and education status. The therapeutic aspects investigated were: therapies performed (onset, frequency and interruption), including physical therapy and surgical intervention; myelomeningocele closure, ventricular peritoneal derivation, orthopedic correction and others. The physical therapy evaluation aimed to identifying the motor development phase, motor condition (coordination, movement amplitude, tonus, muscular retraction and shortening), neurological segment, presence and type of deformity, use of orthotics and assistive devices and mode of locomotion.

The neurological area was determined by evaluation of motor and sensory function, in accordance with the American Spinal Injury Association's (ASIA) International Standards for Neurological Classification of Spinal Cord Injury (8). Classification into thoracic, upper lumbar (L1/L3), lower lumbar (L4/L5) and sacral lesions was done after determining the neurological area (2).

The locomotion mode was considered as walker, wheelchair user and undetermined. Walker children presented gait as their principal mode of locomotion, whereas wheelchair users mostly or exclusively use a wheelchair for locomotion. The undetermined condition represented those children who had yet to define their principal locomotion mode.

Additional data were collected regarding the occurrence and frequency of complications, such as hydrocephalus, decubitus ulcers, urinary infection, fractures, tethered cord and nutritional status. Nutritional status was based on the $\mathrm{Z}$ score for weightfor-stature index, with evaluation conducted by the nutritionist on the multidisciplinary team.

Descriptive analysis of the sample was presented as mean ( \pm standard deviation) or median $(25-75 \%)$, depending on normality assumptions. Categorical variables were presented in the form of absolute and relative frequencies. For association between the primary outcome walking and the explicative variables, chi-square (rxc) tests were used. To measure the effect of exposure to the independent variables on the dependent variable (ability to walk), multiple logistic regression test (Stepwise method) was used. In this procedure, the most significant results ( $\mathrm{F}$ test) of these associations were selected for the initial model. Statistical significance $(\alpha)$ was determined as $5 \%(\mathrm{p} \leq$ $0,05)$. The Statistical Package for Social Science $\left(\mathrm{SPSS}^{\circledR}\right)$ software, version 15.0, was used for all analysis.

\section{Results}

Forty-one children with myelomeningocele were evaluated, with a median age of 5 (2-11) years-old, including 18 boys $(43,9 \%)$ and 23 girls $(55,1 \%)$. Considering the locomotion mode, 15 (36,6\%) were ambulant and 12 (29,3\%) were wheelchair users. Fourteen participants $(34,1 \%)$ were considered undetermined. Ambulant children and those who used a wheelchair were older than those who were yet to determine their mode of locomotion $(\mathrm{p}<0,0001)$. Only five children $(12,2 \%)$ came from families resident in the rural area. The demographic data, according to locomotion mode, are presented in Table 1.

The most observed neurological lesions was in the upper $(\mathrm{n}=12,29,3 \%)$ and lower lumbar spine $(\mathrm{n}=$ $12,29,3 \%)$. The most frequent complications were deformities and urinary infection. Hydrocephalus was observed in 21 children (51,2\%), all of whom had been submitted to ventricular peritoneal derivation. Trophic ulceration occurred in 16 children $(41,5 \%)$, mainly at ischiatic, sacral, malleolar and calcaneus regions. The occurrence of fractures and tethered cord was $17,1 \%$; i.e., 7 children presented these complications. Concerning nutritional status, 22 children $(53,7 \%)$ were malnourished. Moreover, an association was observed between the ability to walk and clinical factors, neurological area and fracture occurrence (Table 2). 
Fujisawa DS, Gois MLCC, Dias JM, Alves EONM, Tavares MS, Cardoso JR.

Table 1 - Demographic data

\begin{tabular}{llccc}
\hline & Ambulant & Wheelchair user & Undetermined & p \\
\hline Age (Md;25-75\%) years & $08(5-9)$ & $08(4.2-11)$ & $02(2-2)$ & $<0,0001$ \\
\hline Gender (n;\%) & & & & \\
\hline Male & $05(27,8 \%)$ & $06(33,3 \%)$ & $07(38,9 \%)$ & 0,367 \\
Female & $10(43,5 \%)$ & $06(26,1 \%)$ & $07(30,4 \%)$ & \\
\hline Origin (n;\%) & & & $12(33,3 \%)$ & 0,622 \\
\hline Urban & $12(33,3 \%)$ & $12(33,3 \%)$ & $02(40 \%)$ & 0 \\
Rural & $03(60 \%)$ & 0 & & \\
\hline
\end{tabular}

Note: $M d=$ median

Table 2 - Association between locomotion and clinical factors

\begin{tabular}{|c|c|c|c|c|}
\hline & Ambulant & Wheelchair user & Undetermined & $p$ \\
\hline \multicolumn{5}{|c|}{ Neurological area $(n ; \%)$} \\
\hline Thoracic & $01(9,1 \%)$ & 07 (63,6\%) & $03(27,3 \%)$ & \multirow{4}{*}{$<0,001$} \\
\hline Upper lumbar & $01(8,3 \%)$ & $05(41,7 \%)$ & $06(50 \%)$ & \\
\hline Lower lumbar & $07(58,3 \%)$ & 0 & $05(41,7 \%)$ & \\
\hline Sacral & $06(100 \%)$ & 0 & 0 & \\
\hline \multicolumn{5}{|l|}{ Scars (n;\%) } \\
\hline Yes & $07(41,2 \%)$ & 07 (41,2\%) & $03(17,6 \%)$ & \multirow{2}{*}{0,131} \\
\hline No & $08(33,3 \%)$ & $05(20,8 \%)$ & $11(45,8 \%)$ & \\
\hline \multicolumn{5}{|c|}{ Deformities (n;\%) } \\
\hline Yes & $10(34,5 \%)$ & $10(34,5 \%)$ & $09(31 \%)$ & \multirow{2}{*}{0,493} \\
\hline No & $05(41,7 \%)$ & $02(16,7 \%)$ & $05(41,7 \%)$ & \\
\hline \multicolumn{5}{|c|}{ Fractures (n;\%) } \\
\hline Yes & 0 & $04(57,1 \%)$ & 03 (42,9\%) & \multirow{2}{*}{0,022} \\
\hline No & $15(44,1 \%)$ & $08(23,5 \%)$ & $11(32,4 \%)$ & \\
\hline \multicolumn{5}{|c|}{ Hydrocephalus (n;\%) } \\
\hline Yes & $07(33,3 \%)$ & $06(28,6 \%)$ & $08(38,1 \%)$ & \multirow{2}{*}{0,848} \\
\hline No & 08 (40\%) & $06(30 \%)$ & $06(30 \%)$ & \\
\hline \multicolumn{5}{|c|}{ Urinary infection $(n ; \%)$} \\
\hline Yes & $10(34,5 \%)$ & $10(34,5 \%)$ & 09 (31\%) & \multirow{2}{*}{0,493} \\
\hline No & $05(41,7 \%)$ & $02(16,7 \%)$ & $05(41,7 \%)$ & \\
\hline \multicolumn{5}{|c|}{ Tethered cord (n;\%) } \\
\hline Yes & $05(71,4 \%)$ & $01(14,3 \%)$ & $01(14,3 \%)$ & \multirow{2}{*}{0,117} \\
\hline No & $10(29,4 \%)$ & $11(32,4 \%)$ & $13(38,2 \%)$ & \\
\hline \multicolumn{5}{|c|}{ Nutritional status } \\
\hline Malnourished & $08(36,4 \%)$ & $06(27,3 \%)$ & $08(36,4 \%)$ & \multirow{3}{*}{0,874} \\
\hline Eutrophic & $04(30,8 \%)$ & $04(30,8 \%)$ & $05(38,5 \%)$ & \\
\hline Overweight & $03(50 \%)$ & $02(33,3 \%)$ & $01(16,7 \%)$ & \\
\hline
\end{tabular}


Children were members of families consisting of at least three persons and of low income. Unemployment was observed in 12 families $(29,3 \%)$, at the time of the evaluation. Of the 26 families that presented a monthly income, $18(43,9 \%)$ earned one to three times the minimum wage and $8(19,5 \%)$ earned over three times the minimum wage. Only 3 families presented no description of monthly income in the social worker's evaluation.

Difficulties referred to the proposed treatment were reported by 31 participants $(75,6 \%)$. These problems referred to difficulties attaining access to transport, purchase of materials, medication, orthotics and scheduling of consultations, exams and surgeries. Socioeconomic conditions presented no association with walking ability.

Of 41 children evaluated, only $3(7,3 \%)$ did not receive physical therapy regularly, two ambulant and one wheelchair user. Orthotics were used by 21 children (51,2\%), 16 ankle-foot orthosis (AFO), 4 hip-knee-ankle-foot orthosis (HKAFO) and 1 insole. Assistive devices were not used by 36 children $(87,8 \%)$. Of the 5 children who used such assistive devices, $3(7,3 \%)$ required Canadian crutches and 2 $(4,9 \%)$ required walkers.

In relation to surgical interventions, the most frequently performed were myelomeningocele closure, orthopedic correction and ventricular peritoneal derivation $(31,7 \%)$. Only one child had not been submitted to any surgical intervention. All wheelchair users and those children who had yet to define their mode of locomotion had undergone surgical intervention. Among the therapeutic factors, the use of assistive devices $(p=0,023)$ and surgical interventions $(p=0,017)$ showed an association with walking ability (Table 3 ).

The statistically significant results of associations between explicative variables on the primary outcome (ambulant activity) were selected for the model used in multivariate analysis. The following variables were included in this model: age, neurological area, fracture occurrence, type of surgery and assistive devices. The final logistic regression model was unable to identify variables that could predict walking ability in children presenting myelomeningocele.

\section{Discussion}

The predominance of female gender (23 girls: 18 boys) was relatively low in comparison to the findings of other studies (9). Children presenting myelomeningocele acquire the ability to walk around 37 months-old; thus, at 2 years it is not possible to determine whether the child will be ambulant or a wheelchair user (10). A study conducted in South Africa showed that ambulant activity was more frequent in patients from Cape Town (urban area) than

Table 3 - Association between locomotion mode and therapeutic factors

\begin{tabular}{|c|c|c|c|c|}
\hline & Ambulant & Wheelchair user & Undetermined & $\mathrm{p}$ \\
\hline \multicolumn{5}{|l|}{ Walking aids $(\mathrm{n} ; \%)$} \\
\hline Canadian crutches & $03(100 \%)$ & 0 & 0 & \multirow{3}{*}{0,023} \\
\hline Walker & $02(100 \%)$ & 0 & 0 & \\
\hline Not used & $10(27,8 \%)$ & $12(33,3 \%)$ & $14(38,9 \%)$ & \\
\hline \multicolumn{5}{|l|}{ Types of surgery $(n ; \%)$} \\
\hline Closure & $02(28,6 \%)$ & $02(28,6 \%)$ & $03(42,9 \%)$ & \multirow{3}{*}{0,345} \\
\hline Closure + orthopedic correction & $06(66,7 \%)$ & $03(33,3 \%)$ & 0 & \\
\hline Closure + orthopedic & $05(38,5 \%)$ & $05(38,5 \%)$ & $03(23,1 \%)$ & \\
\hline Correction + derivation & - & - & - & \multirow{3}{*}{0,017} \\
\hline Closure + derivation & $01(9,1 \%)$ & $02(18,2 \%)$ & $08(72,7 \%)$ & \\
\hline Not performed & $01(100 \%)$ & 0 & 0 & \\
\hline \multicolumn{5}{|l|}{ Physical therapy (n;\%) } \\
\hline Yes & $13(34,2 \%)$ & $11(28,9 \%)$ & $14(36,8 \%)$ & \multirow{2}{*}{0,247} \\
\hline No & $02(66,7 \%)$ & $01(33,3 \%)$ & 0 & \\
\hline
\end{tabular}


those residents in the rural area (11). In the present study, it was not possible to evaluate the interference of this factor on walking prognosis, since only five myelomeningocele patient lived in the rural area.

The lumbar spine was most affected, confirmed by other studies $(11,12)$, though when considered in isolation, no predominance between upper and lower lumbar segments was found. In our study, no child presented lesion at cervical spine.

Neurological area interfered in walking ability, given that wheelchair users presented compromise of the thoracic and upper lumbar; whereas ambulant children presented lower lumbar and sacral impairments. Functional ability and gait pattern of myelomeningocele patients are variable, and mainly dependent on the local of neurological lesion (12). Therefore, neurological lesion is a significant clinical factor in walking ability in children presenting myelomeningocele. In their study, Iborra, Pagés and Cuxart also identified neurological area as the main factor determining walking prognosis in children presenting myelomeningocele (10).

It is worth pointing out that of the 12 wheelchair users, only four presented orthostatism and/ or nonfunctional ambulant activity. The multidisciplinary team should be aware of the importance of performing orthostatism and nonfunctional ambulant activity, due to its physiological benefits. During the evaluation, children's guardians revealed they did not possess the orthotics and other equipment required for performing such activities.

The most frequently found deformities and contractures in this study were scoliosis, kyphoscoliosis, flexion with adduction or hip adduction, knee flexion, calcaneal valgus and talipes equines. Scoliosis and kyphoscoliosis are frequently observed in myelomeningocele children, present in over $45 \%$ of cases, and related to age and to higher neurological lesions $(7,10)$. Pelvic obliquity $(40 \%)$ and hip flexion contracture $(27,3 \%)$ also occur frequently in myelomeningocele children (10). Gait asymmetry is related to the presence of unilateral or asymmetric contracture and is not only due to hip instability in children presenting lower lumbar neurological impairment (13). Persistent dorsiflexion resulted from plantiflexor muscle weakness, increased hip and knee flexion and anterior inclination of the pelvis; i.e., compensatory strategies are implemented to maintain the correct foot position and ambulant activity (14).
Children presenting neurogenic bladder can develop clinical complications resulting from urinary incontinence. Urinary infection is a frequent complication in children presenting neurogenic bladder, as verified in this study. Moreover, girls that present urinary incontinence show greater risk of developing low self-esteem (15).

Hydrocephalus frequency $(51,2 \%)$ was lower than rates reported in previous studies (9-11), and showed no significance in relation to walking prognosis in myelomeningocele children. However, functional independence in adolescents presenting myelomeningocele, evaluated by means of the Functional Independence Measure (FIM), suffered modifications according to the presence or absence of hydrocephalus, locomotion dominion, personal hygiene and transferences (9).

Decubitus ulcers are a common complication, occurring in $32 \%$ of myelomeningocele children as result from diminished or loss of sensitivity(11). Ulcers identified in 17 children $(41,5 \%)$ in the present study, demand increased attention from the child, family members and professionals involved in relation to preventive care.

Seven children had a history of fractures in the lower extremities, four were wheelchair users and three had yet to define their mode of locomotion. The fractures occurred in the femur, the proximal and distal thirds, and the tibia; they were painless and not related to trauma. Wheelchair users suffered fractures at high, thoracic and lower lumbar spine, which, according to Quan et al. present low mineral density (16). The occurrence of fractures is probably result of osteoporosis (7), osteopenia (12), lack of ambulant activity and less frequent movement in the lower extremities (17), as well as other aspects that might be involved. Thus, fractures occur as a result of the influence of several factors, including the local of neurological lesion and mode of locomotion adopted, rather than as an intervenient factor in walking ability.

Identification of $17,1 \%$ patient with tethered cord is in agreement with that reported by Didelot (7). Parents and professionals involved in accompanying myelomeningocele children should maintain constant supervision of signs and symptoms of tethered cord, since this can lead to a worsening gait pattern in certain cases (18).

The nutritional status of the myelomeningocele children differed from investigations conducted in 
other countries, which report the risk of overweight and obesity (19-20). The frequency of malnourished children is probably due to the socioeconomic conditions of their respective families, suggesting that more in-depth studies regarding nutritional status and the aspects involved should be developed.

The socioeconomic conditions of the majority of children's families proved to be precarious. The 12 children who were members of families in which the principal earner was unemployed survived on the monthly benefit provided by the government to assist in the treatment of persons with disabilities. The value of this benefit is $\mathrm{R} \$ 350,00$, approximately US\$ 150,00 , which is insufficient for the survival of the family and was not used to subsidize the child's care and treatment requirements. The benefit provided by the government aimed at subsidizing the treatment of persons with disabilities, is only offered to children of families whose monthly income is less than $25 \%$ of the minimum wage. The minimum wage in Brazil is currently $\mathrm{R} \$ 380,00$ (approx. US\$ 190,00). Reiterating that all the families included at least three members and that monthly income covered housing, food and hygiene and the child's treatment costs, even those families earning over three times the minimum wage presented difficulties in conducting the treatment indicated.

According to their mothers, the three children who did not receive physical therapy interrupted this treatment due to difficulties regarding transport to the service; i.e., they did not have the financial resources or access to public transport. Children with undetermined mode of locomotion received physical therapy regularly, since this is required to develop the physical and motor conditions necessary for walking or wheelchair use. However, the need for physical therapy persists even after determining the locomotion mode, since complications, such as deformities and contractures, can evolve with worsening of the gait pattern. The majority of children required assistance to complete daily life activities; thus, maximization of their functionality is likely to be developed in therapeutic programs (6).

AFO maintains the ankle at $90^{\circ}$ and is used for adequate positioning in ambulant children, wheelchairs users and those who have yet to define their locomotion mode; thus, it is a frequently indicated orthosis for myelomeningocele children, as verified in this study. The AFO provides improvement in gait pattern, particularly in children presenting L4 and L5 lesions, since it diminishes the degree of dorsiflexion and prevents tibia advancement $(14,21)$. The use of orthoses with mechanisms that favor walking in children presenting higher neurological lesions, such as RGO (Reciprocating Gait Orthoses) and HGO (Hip Guidance Orthosis) was not found (22).

The use of Canadian crutches and walkers only occurred among ambulant children; thus, although this was statistically significant, it referred to the need for assistive devices among those who presented the possibility of walking. Accordingly, the use of assistive devices is not a determining factor in walking ability of children presenting myelomeningocele, but a necessary resource for walking.

It should be highlighted that even wheelchair users should make use of assistive devices when performing nonfunctional ambulant activity, since several physiological benefits result from orthostatism and ambulant activity.

Myelomeningocele closure was performed within the first two days of life, in most cases; only one child was not submitted to surgical intervention and presented a reduced diameter non-opened. The 24 children $(58,5 \%)$ who underwent ventricular peritoneal derivation were submitted to surgery during the first week of life. Some studies report surgical intervention indices greater than $60 \%$ in the treatment of hydrocephalus (10). No child was submitted to fetal surgery, though some authors have reported that myelomeningocele closure prior to birth leads to diminished occurrence of hydrocephalus, consequently avoiding ventricular peritoneal derivation (23-24).

In the present study, verification showed that ambulant children and wheelchair users were submitted to surgical interventions with similar frequencies in some cases, with greater differences among children who had yet to determine their mode of locomotion. Myelomeningocele closure was performed in seven children ( 2 ambulant, 2 wheelchair users and 3 undetermined). Myelomeningocele closure followed by ventricular peritoneal derivation occurred in 11 children ( 1 ambulant, 2 wheelchair users and 8 undetermined). Myelomeningocele closure, later followed by ventricular peritoneal derivation and orthopedic corrections was identified in 13 children (5 ambulant, 5 wheelchair users and 3 undetermined).

Myelomeningocele closure, later followed by orthopedic corrections, occurred in nine children (6 ambulant and 3 wheelchair users). Orthopedic corrections were more frequent among ambulant 
children than wheelchair users and had not been performed on children yet to define their locomotion mode. Orthopedic corrections were performed on 22 children, of which 11 were ambulant, indicating that they are required to promote walking capacity. Alignment of the lower extremities in children presenting myelomeningocele can be performed by means of orthopedic corrections. Thus, given the results obtained, it is possible to affirm that orthopedic corrections are required to promote walking capacity in myelomeningocele children, in agreement with fact that the surgical factor was statistically identified as a significant factor in walking capacity (25).

\section{Conclusion}

The local of neurological lesion was a determinant clinical factor for walking prognosis in children presenting myelomeningocele. Participants presenting upper lumbar and thoracic lesions were wheelchair users, whereas ambulant children presented lower lumbar and sacral neurological deficits. Fractures were also inversely associated with walking ability, though they are result of many aspects, including lack of physical and ambulant activity. Unfavorable socioeconomic conditions make conduction of treatment more difficult, but apparently do not interfere in walking prognosis in children presenting myelomeningocele. Among therapeutic factors, the use of assistive devices and surgical interventions were associated with walking prognosis in children presenting myelomeningocele, demonstrating that these are required to promote ambulant activity. In this study it was not possible to conclude that the intervenient factors were predictive of walking ability of children presenting myelomeningocele.

\section{References}

1. Piatt JH. Treatment of myelomeningocele: a review of outcomes and continuing neurosurgical considerations among adults. J Neurosurg Pediatr. 2010;6(6) 515-25

2. Aguiar MJB, Campos AS, Aguiar RALP, Lana AMA, Magalhães RL, Babeto LT. Neural tube defects and associated factors among liveborn and stillborn infants. J Pediatr. 2003;79(2):129-34.
3. Au KS, Ashley-Koch A, Northrup H. Epidemiologic and genetic aspects of spina bifida and other neural tube defects. Dev Disabil Res Rev. 2010;16(1):6-15.

4. Sandler AD. Children with spina bifida: key clinical issues. Pediatr Clin North Am. 2010;57(4):879-92.

5. Bartonek A. Motor development toward ambulation in preschool children with myelomeningocele: a prospective study. Pediatr Phys Ther. 2010;22(1):52-60.

6. Norrlin S, Strinnholm M, Carlsson M, Dahl M. Factors of significance for mobility in children with myelomeningocele. Acta Paediatr. 2003;92(2):204-10.

7. Didelot WP. Currents concepts in myelomeningocele. Curr Opin Orthop. 2003;14(6):398-402.

8. Maynard FM JR, Bracken MB, Creasey G, Dittuno JF, Donovan WH, Ducker TB, et al. International Standards for Neurological and Functional Classification of Spinal Cord Injury. American Spinal Injury Association. Spinal Cord. 1997;35(5):266-74.

9. Verhoef M, Barf HA, Post MWM, van Asbeck FWA, Gooskens RHJM, Prevo AJH. Functional independence among young adults with spina bifida, in relation to hydrocephalus and level of lesion. Dev Med Child Neurol. 2006;48(2):114-9.

10. Iborra J, Pagés E, Cuxart A. Neurological anormalities, major orthopaedic deformities and ambulation analysis in a myelomeningocele population in Catalonia (Spain). Spinal Cord. 1999;37(5):351-7.

11. Buccimazza S, Molteno C, Dunne T. Pre-school follow-up of a cohort of children with myelomeningocele in Cape Town, South Africa. Ann Trop Paediatr. 1999;19(3):245-52.

12. Valtonen KM, Goksör LA, Jonsson O, Mellström D, Alaranta HT, Viikari-Juntura ER. Osteoporosis in adults with meningomyelocele: an unrecognized problem at rehabilitation clinics. Arch Phys Med Rehabil. 2006; 87(3):376-82.

13. Gabrieli APT, Vankoski S, Dias LS, Milani C, Lourenço A, Filho LJ. Laboratorial analysis of the myelomeningocele gait of lower lumbar level and unilateral hip instability. Acta Ortop Bras. 2004;12:91-8.

14. Gutierrez EM, Bartonek A, Haglund-Akerlind Y, Saraste H. Characteristic gait kinematics in persons with lumbosacral mielomeningocele. Gait Post. 2003; 18(3):170-7. 
15. Moore C, Kogan BA, Parekh A. Impact of urinary incontinence on self-concept in children with spina bifida. J Urol. 2004;171(4):1659-62.

16. Quan A, Adams R, Ekmark E, Baum M. Bone mineral density in children with myelomeningocele. Pediatrics. 1998;102(3):E34.

17. Chapman D. Context effects on the spontaneous leg movements of infants with spina bifida. Pediatr Phys Ther. 2002;14(2):62-73.

18. 18. Schoenmakers MAGC, Gooskens RHJM, Gulmans VAM, Hanlo PW, Vandertop WP, Uiterwaal CSPM, et al. Long-term outcome of neurosurgical untethering on neurosegmental motor and ambulation levels. Dev Med Child Neurol. 2003;45(8):551-5.

19. Van den Berg-Emons HJG, Bussmann JBJ, Meyerink HJ, Roebroeck ME, Stam HJ. Body fat, fitness and level of everyday physical activity in adolescents and young adults with meningomyelocele. J Rehab Med. 2003; 35(6):271-5.

20. Littlewood RA, Trocki O, Shepherd RW, Shepherd K, Davies PSW. Resting energy expenditure and body composition in children with mielomeningocele. Pediatr Rehabil. 2003;6(1):31-7.
21. Wolf SI, Alimusaj M, Rettig O, Döderlein L. Dynamic assist by carbon fiber spring AFOs for patients with myelomeningocele. Gait Post. 2008;28(1):175-7.

22. Campbell JH. Outcome study: the progression of spinal deformity in paraplegic children fifted with reciprocating gait orthoses. J Prosthet Orthot. 1999; 11:79-84.

23. Manning SM, Jennings R, Madsen JR. Pathophysiology, prevention, and potential treatment of neural tube defects. Ment Retard Dev Disabil Res Rev. 2000;6(1):6-14.

24. Farmer D. Fetal surgery. BMJ. 2003;326(7387):461-2.

25. Danielsson AJ, Bartonek A, Levey E, McHale K, Sponseller P, Saraste H. Associations between orthopaedic findings, ambulation and health-related quality of life in children with myelomeningocele. J Child Orthop. 2008;2(1):45-54.

Received: 10/15/2010

Recebido: 15/10/2010

Approved: 03/18/2011

Aprovado: 18/03/2011 